Meta

Journal des traducteurs

Translators' Journal

\title{
Does Early Bilingual Acquisition Affect Hemispheric Preferences during Simultaneous Interpretation?
}

\section{Josiane F. Hamers, Sylvie Lemieux et Sylvie Lambert}

Volume 47, numéro 4, décembre 2002

URI : https://id.erudit.org/iderudit/008038ar

DOI : https://doi.org/10.7202/008038ar

Aller au sommaire du numéro

Éditeur(s)

Les Presses de l'Université de Montréal

ISSN

0026-0452 (imprimé)

1492-1421 (numérique)

Découvrir la revue

Citer cet article

Hamers, J. F., Lemieux, S. \& Lambert, S. (2002). Does Early Bilingual Acquisition Affect Hemispheric Preferences during Simultaneous Interpretation? Meta, 47(4), 586-595. https://doi.org/10.7202/008038ar

\section{Résumé de l'article}

À partir de données obtenues dans une étude préalable (Lambert, 1993) et basée sur une approche propositionnelle développée par Lemieux (1995), qui a su peaufiner la qualité de l'évaluation de l'interprétation afin de déterminer la supériorité de l'oreille droite au début d'un passage ainsi que la supériorité de l'oreille gauche à la fin du passage, cette étude examine le rôle de l'expérience, l'âge de l'interprète et l'âge du bilinguisme, tous des facteurs possibles pouvant influencer le contrôle hémisphérique de l'interprétation. Les résultats indiquent que le nombre d'années d'expérience influence la qualité de l'interprétation dans le sens que les interprètes chevronnés interprètent mieux, quelle que soit l'oreille. Mais les résultats semblent indiquer que les préférences hémisphériques pour l'analyse linguistique sont plus volontairement régies par l'interprète que prévu. 


\title{
Does Early Bilingual Acquisition Affect Hemispheric Preferences during Simultaneous Interpretation?
}

\author{
JOSIANE F. HAMERS \\ Laval University, Québec, Canada \\ SYLVIE LEMIEUX \\ Laval University, Québec, Canada \\ SYLVIE LAMBERT \\ University of Ottawa, Ottawa, Canada
}

\begin{abstract}
RÉSUMÉ
À partir de données obtenues dans une étude préalable (Lambert, 1993) et basée sur une approche propositionnelle développée par Lemieux (1995), qui a su peaufiner la qualité de l'évaluation de l'interprétation afin de déterminer la supériorité de l'oreille droite au début d'un passage ainsi que la supériorité de l'oreille gauche à la fin du passage, cette étude examine le rôle de l'expérience, l'âge de l'interprète et l'âge du bilinguisme, tous des facteurs possibles pouvant influencer le contrôle hémisphérique de l'interprétation. Les résultats indiquent que le nombre d'années d'expérience influence la qualité de l'interprétation dans le sens que les interprètes chevronnés interprètent mieux, quelle que soit l'oreille. Mais les résultats semblent indiquer que les préférences hémisphériques pour l'analyse linguistique sont plus volontairement régies par l'interprète que prévu.
\end{abstract}

\begin{abstract}
Based on data from an earlier study (Lambert 1993), and on a propositional approach developed by Lemieux (1995), who refined quality of interpretation measurements sufficiently to determine a right-ear superiority at the beginning of a message and a left-ear superiority at the end of a message, the present study went one step further to examine the role played by experience, age and age of bilinguality, all possible factors influencing the hemispheric control of interpretation. Results indicated that the number of years of experience influences the quality of interpretation in that the more experienced interpreters interpreted better, regardless of ear of input. But overall results point to the possibility that hemispheric preferences for linguistic analysis might be much more under an interpreter's voluntary control than first anticipated.
\end{abstract}

\section{MOTS-CLÉS/KEYWORDS}

simultaneous interpretation, cerebral dominance, propositional analysis, bilingualism

After more than a century of clinical and experimental research, it is now well established that, at least among right-handed adults, language is dependent predominantly on the cerebral activity of the left cerebral hemisphere. However, it was not until the 1970s that the issue of the bilingual brain was addressed in a systematic way. In 1978, for example, Albert \& Obler came to the conclusion that "language is organized in the brain of a bilingual in a manner different from that which might have been predicted by studies of cerebral organization for language in monolinguals" (p. 243). 
In recent decades, the role of the right hemisphere, both in second language learning and in semantic processing, has been recognized. A number of studies concluded that bilinguals are lateralized in a different way than monolinguals and that hemispheric patterns of early bilinguals differ from those of late bilinguals. In infant bilinguals, lateralization should more closely resemble language lateralization in monolinguals, whereas in late bilinguals, language processing should be more under bilateral control. Besides age of acquisition, language lateralization in bilinguals should also be influenced by the mode of language learning-formal learning requiring more left-hemisphere involvement, and informal learning, more righthemisphere involvement-(Vaid 1987). The degree of competence attained in the second language seems also to play a role, with the suggestion that greater righthemisphere involvement is evident during the early learning stages (Lemieux 1995). Finally, language difference and script differences may also call on the two hemispheres differently (for a review, see Hamers \& Blanc 2000).

Nonetheless, these recent views have been challenged by Vaid and Hall (1991). By reviewing the literature on hemispheric preferences in monolinguals and bilinguals in clinical and normative populations, Vaid \& Hall conclude that there is no clear evidence for differential neuropsychological implications of the bilingual experience. They point out that the importance of task variables has generally been under-represented by investigators. More recently, studies have paid greater attention to the task. Different linguistic judgements are differentially lateralized in monolinguals. For example, semantic judgements may be more right-hemisphere lateralized than the other types of linguistic judgements that are left-hemisphere lateralized.

The task-specific approach is particularly relevant in the study of simultaneous interpretation. Simultaneous interpretation is a complex linguistic task, requiring specific cognitive skills. Almost all features of information processing are relevant to interpretation. The interpreter is expected to listen to the speaker, extract the meaning, store the information so as to relay it to the listener as accurately as possible in another language. What is characteristic of interpreters is not their bilinguality, which includes native-like competence in at least two languages, as much as their capacity to decode a message in the source language while simultaneously re-encoding it in the target language with the highest possible fidelity (Hamers \& Blanc 1989). While interpreters are highly competent bilinguals, they also have to perform a very demanding and unusual specific linguistic task.

According to Paradis (1984), at least three neurofunctional systems are activated during interpretation: one for the source language, one for the target language, and one for the connections between source and target languages. The latter differ depending on the direction of interpretation: interpreting one passage from L1 to L2 might not call on the same connections as interpreting the same passage from L2 to L1. Interpretation appears as an autonomous linguistic function that is acquired through training and that seems independent from the individual's bilingual competence.

Recent research appears to indicate that both hemispheres are activated during simultaneous interpretation (Fabbro, Gran, Basso and Bava, 1990). However, the degree of involvement varies with the amount of experience acquired in interpretation. Several studies (Fabbro, Gran and Gran 1991; Fabbro, Gran, Basso \& Bava 1991; Spiller-Bosatra, Darò, Fabbro \& Bosatra 1990) have demonstrated that hemispheric preferences of professional interpreters are different from the cerebral organization 
of student interpreters or of fluent bilinguals. Skilled interpreters are superior to student interpreters in detecting semantic errors, and they show a right-ear (RE) superiority for detecting semantic errors in their dominant or mother-tongue (L1) and a left-ear (LE) superiority for detecting semantic errors in their secondarilyacquired language (L2). Student interpreters pay more attention to syntactic features of the source language, in this case, their L2. According to Gran and Fabbro (1989), training in simultaneous interpretation tends to modify hemispheric specialization and to produce a reorganization of attentive functions for verbal stimuli from both ears (p. 134). Fabbro et al. (1990) failed to demonstrate that skilled interpreters would have a change in hemispheric preference according to the fact that they translated from L1 to L2 or from L2 to L1. The details of these studies are both complex and intriguing.

Using a shadowing task, Kraushaar and Lambert (1987) observed that francophone and anglophone student-interpreters, who in this case were all right-handed, had a RE preference when shadowing in their mother tongue, whereas no preference was observed in their L2. They further demonstrated that what was true for adolescent and adult bilinguals, childhood bilinguals-i.e., those who were introduced to their L2 in childhood-failed to show a hemispheric preference in their mother tongue, whereas they had a left-hemisphere preference in their L2. Using an interference paradigm, Green, Schweda-Nicholson, Vaid, White \& Steiner (1990) compared monolinguals, bilinguals and interpreters performing two tasks: shadowing and either paraphrasing (for the monolinguals) or interpreting (for the bilinguals and the interpreters). For the monolinguals, interference was greater for the left hemisphere for both tasks. For the bilinguals and the interpreters, left hemispheric preferences were evident in the shadowing task, but not in the interpretation task. This would indicate that both hemispheres are involved in simultaneous interpretation.

These findings, however, are not in agreement with an observation of interpreters at work. Lambert (1993) reported that skilled interpreters tend to use only one earphone of a pair of binaural headphones, and that the other ear is partially uncovered so that, as many later explained, they can monitor their own output. Comparing three listening conditions in interpretation, she demonstrated that, for both skilled interpreters and student interpreters, the output was superior in two monaural conditions than in a binaural condition-i.e., the normal both-ears input conditionand that there was also a tendency for the LE condition to be better than the RE condition.

A second hypothesis that was put to test concerns the strategies used by interpreters. Gran (1989) observed that interpreters tend to use two main strategies, requiring left or right hemispheric involvement to different degrees: a word-for-word or literal translation and a meaning-oriented translation. In the literal strategy, the left hemisphere would have a greater involvement, whereas in the meaning-oriented strategy, right hemisphere involvement would be more prominent. Fabbro et al. (1990) found major differences in interference in the two strategies: interference appears much more frequently in a meaning-oriented translation. The authors, however, failed to establish a hemispheric preference in either strategy, and consequently concluded that both hemispheres are involved during interpretation.

Using data obtained in the same conditions as in Lambert's 1993 study, Lemieux (1995) failed to verify that interpretation was superior in monaural conditions than 
in bilingual conditions. As in the Lambert study, who based herself on the studies of Barik (1973), three measures to assess interpreters' performance were used, namely errors, omissions and additions. Furthermore, Lemieux developed a propositional analysis enabling her to identify the propositions of the output language that were identical or similar to those of the source language. Evidence from studies in cognitive psychology (Lemieux \& Hamers, in press) prompted the authors to consider that propositional analysis might be a good measure of the quality of the interpretation. It should be noted that, as we confirmed in the study, this approach is not independent from the more traditional measures (errors, omissions and additions). It was expected that this more refined approach to the quality of the interpretation would make it easier to identify any existing hemispheric preference.

In line with the findings of Fabbro and his colleagues and of Green et al. (1990), the following assumptions can be made regarding the interpretation task: both hemispheres contribute to the task to varying degrees. The left hemisphere may process more morpho-syntactic aspects of the source language, whereas the right hemisphere may process the more pragmatic aspects by elaborating the macrostructure, establishing global coherence and construing the situational model. The production in the target language depends on the pragmatic aspects in the source language. A new microstructure is elaborated with the situational model as a starting point; this microstructure, under the control of the right hemisphere, will guide the choice of the grammatical structures and of the words in the target language that are under the control of the left hemisphere.

Lemieux did not observe any difference in the quality of interpretation under the three listening conditions used by Lambert. However, when she took into consideration the time when the listening condition occurred (the beginning, the middle, or the end of the interpretation), she found the RE condition to be superior at the beginning of the interpretation, and the LE condition to be superior at the end of the interpretation. Whereas Fabbro et al. (1990) failed to demonstrate that the two major interpretation strategies are under different hemisphere control, the Lemieux analysis supports this hypothesis. Of course Fabbro et al. (1990) did not analyze according to time period in the interpretation process. Lemieux's findings prompted her to propose the following model: when the interpreter begins translating an argumentative text, s/he relies on a literal strategy, thus performing sequential information processing, thereby relying on the left hemisphere. Once the interpreter becomes acquainted with the structure of the text, the task becomes more of a meaningoriented translation, calling for more global information processing. In this case, the LE condition is the more advantageous one. There would thus be a change in strategy once the interpreter has identified the category of the text and the elements of the superstructure. In other words, receiving the source message in the RE at the beginning of the interpretation and in the LE at the end seems to represent the optimal situation. In fact, the switch-over may become a normal adaptation for skilled translators, and the release of one earphone may be simply a manifestation of the switch.

The present study addresses the questions of the role played by experience, age and age of bilinguality. In interpretation, several of the studies from the Trieste School of Interpretation mention a change in hemispheric control linked to the experience of the interpreter. That is, as previously mentioned, there is evidence that trained interpreters have a different hemispheric control over their output than untrained 
bilinguals. We also raise the question as to whether age might be a factor influencing the hemispheric control of interpretation. Finally, we check to see if any differences can be observed in relation to the type of bilinguality.

\section{Methodology}

\section{Experimental set-up}

Because we analyzed the data originally collected by Lambert (1993), we will first give a brief description of the methodology used in her study. Twenty-three subjects, skilled interpreters or student interpreters at the University of Ottawa's School of Translation and Interpretation, received a source text in their second language to be interpreted into their dominant language under different listening conditions. Two source texts were used, one in English and one in French. All Ss received a threeminute warm-up period during which the source text reached both ears; the rest of the source text was divided into three equal parts (A, B and C), each three minutes long. Ss would receive each part, either in the left ear (LE), the right ear (RE), or both ears $(\mathrm{BE})$. The order in which the three conditions were received was counterbalanced across Ss.

Sennheiser stereophonic headphones were used, as well as two Panasonic (RQ495) record-players, one for playing the source-text, and one for recording the S's output. The experimenter controlled the ear of input but Ss were free to modify the volume at will. Ss were asked to complete the interpretation of the text, but were not told about the different listening conditions.

Ss completed a questionnaire (Lambert \& Lambert 1985) concerning their preferred ear, language acquisition history, language use, perceived linguistic competence in different languages and handedness (the Edinburgh Handedness Inventory), as well as basic information (age, sex, mother-tongue, language competence, etc.).

Only the protocols of 16 Ss ( 7 males and 9 females) who were clearly righthanded were analyzed in the present study. Of these, 6 had French as their mother tongue and dominant language, with English as their second language; the remaining 10, all dominant in English, had either English as their mother tongue, English together with another language as their mother tongue, or another language (an African language) together with a childhood acquisition of English; all 10 declared that French was their second language. The age of the Ss varied from 25 to 60 and their experience in interpretation ranged from 1 month to 20 years. Six Ss were clearly infant bilinguals in French and English, whereas 6 were adolescent bilinguals; for the remaining 4 , it was less obvious or difficult to reconstruct.

Recording of the source texts was completed at the Division for Interpretation at the Secretary of State in Hull, Quebec: both texts—official argumentative speeches produced by former prime ministers-were read by native speakers at rates of approximately 108 words per minute. The recording was done under stereophonic conditions and care was taken to equilibrate the stereophonic effect.

\section{Text analysis}

For the two source texts and the target texts, a propositional analysis was conducted at Laval University. For each part of both source texts, a text base (microstructure) 
was constructed using an algorithm developed by Turner and Green (1978) and based on the Kintsch and van Dijk (1978) approach (1. Modified arguments of predicate propositions; 2. Connected arguments of predicate propositions; 3 . Predicate propositions; 4 . Modifiers of predicate propositions; 5 . Modified arguments of circumstantial propositions; 6. Circumstantial propositions; 7. Other connective propositions within clause; 8 . Connective propositions between clauses and 9. Repeat).

The target texts were proportionalized using the same procedure. The base text for each part of the output text was compared with the base text in the source language. For each condition, the base text of the target language was compared with the base text in the source language. The following scores were calculated: (1) percentage of identical and similar propositions; (2) percentage of errors; (3) percentage of omissions and (4) percentage of additions.

The propositional analysis of the two source texts indicated that they were similar in many respects. Both texts were argumentative; they both dealt with the same topic (welcoming a visiting foreign prime minister) and contained a similar number of propositions: the French text contained 610 propositions (200, 217 and 193 for parts A, B and C, respectively) and the English text, 613 propositions (200, 202 and 211 , respectively).

\section{Results of the main study}

The results of the main study (Lemieux 1995) conducted on the 16 protocols of the right-handed Ss can be summarized as follows: whereas the hypothesis was put forward that the monaural conditions would yield better results than the binaural condition, and that the left-ear, or right-hemisphere condition would be superior to the right-ear, left-hemisphere condition, no significant differences were observed among the three conditions. However, when the time of the conditions was taken into consideration, Ss who received section A in the right ear (LH) had a superior performance than those who received section A in the left ear or in both ears; this was significant for two of the four measures, namely, the percentage of identical or similar propositions $(\mathrm{t}=6.404 ; \mathrm{p}<.01)$ and for the omissions $(\mathrm{t}=3.647 ; \mathrm{p}<.01)$; a similar trend could be observed for the remaining two measures (errors and additions).

In the same vein, Ss who received the final section (C) in the left ear $(\mathrm{RH})$ performed better than those who received section $\mathrm{C}$ in the right ear or in both ears.

TABLE 1

D scores ${ }^{1}$ on four measures of interpretation

for the monaural conditions used in sections $\mathrm{A}$ and $\mathrm{C}$

Section A

Section C

\begin{tabular}{|l||c|c|c||c|c|c|}
\hline & Left Ear & Right Ear & P level & Left Ear & Right Ear & p level \\
\hline $\mathrm{n}$ & 6 & 5 & & 6 & 5 & \\
\hline Identical & -5.56 & +7.90 & .01 & +6.34 & -5.32 & .05 \\
\hline Errors & +1.87 & -0.68 & .10 & -1.74 & -0.05 & $\mathrm{~ns}$ \\
\hline Omissions & +4.39 & -6.85 & .01 & -4.39 & +5.20 & .05 \\
\hline Additions & +0.69 & -4.54 & $\mathrm{~ns}$ & -1.41 & +2.51 & $\mathrm{~ns}$ \\
\hline
\end{tabular}


These results prompted Lemieux (1995) to propose a dynamic model of interpretation: the optimal condition would be to receive the source language in the right ear at the beginning of the interpretation and in the left ear at the end of the interpretation.

\section{Results}

Correlations between age, experience and measures

\section{TABLE 2}

Correlations between age, experience and the four measures of interpretation $(n=6)$

\begin{tabular}{|l|c|c|c|c|}
\hline Age & Identical & Errors & Omissions & Additions \\
\hline Experience & $\begin{array}{c}-.0229 \\
\mathrm{~ns}\end{array}$ & $\begin{array}{c}.0062 \\
\mathrm{~ns}\end{array}$ & $\begin{array}{c}-.0362 \\
\mathrm{~ns}\end{array}$ & $\begin{array}{c}.1788 \\
\mathrm{~ns}\end{array}$ \\
\hline \hline Identical & -0236 & $\begin{array}{c}-.1583 \\
\mathrm{~ns}\end{array}$ & $\begin{array}{c}.0541 \\
\mathrm{~ns}\end{array}$ & $\begin{array}{c}.0112 \\
\mathrm{~ns}\end{array}$ \\
\hline Errors & - & $\begin{array}{c}. .5072 \\
\mathrm{~ns}=.042\end{array}$ & $\begin{array}{c}-.8818 \\
\mathrm{p}=.000\end{array}$ & $\begin{array}{c}-.1157 \\
\mathrm{~ns}\end{array}$ \\
\hline Omissions & & - & $\begin{array}{c}.0448 \\
\mathrm{~ns}\end{array}$ & $\begin{array}{c}-.3152 \\
\mathrm{~ns}\end{array}$ \\
\hline Additions & & & - & $\begin{array}{c}.3080 \\
\mathrm{~ns}\end{array}$ \\
\hline
\end{tabular}

As can be seen in Table 2, when the results of the 16 Ss are analyzed, neither age nor experience seem to be correlated to any of the four measures. This table indicates that identical and similar propositions are highly correlated with omissions $(\mathrm{r}=-.8818$; $\mathrm{p}=.000)$ and to a lesser extent with errors $(-.5072 ; \mathrm{p}=.042)$. Thus, the more the propositions are identical or similar to the source text, the fewer omissions or errors in the output.

\section{TABLE 3}

Correlations between age, experience and the four measuresof interpretation for the Ss who received section $A$ in the right ear $(n=6)$

\begin{tabular}{|c|c|c|c|c|}
\hline & Identical & Errors & Omissions & Additions \\
\hline Age & $\begin{array}{c}-.0266 \\
\mathrm{~ns}\end{array}$ & $\begin{array}{c}-.8391 \\
\mathrm{p}=.037\end{array}$ & $\begin{array}{c}.5486 \\
\text { ns }(p=.260)\end{array}$ & $\begin{array}{c}.3333 \\
\text { ns }\end{array}$ \\
\hline Experience & $\begin{array}{c}-.4399 \\
\mathrm{~ns}\end{array}$ & $\begin{array}{c}-.8274 \\
p=.042\end{array}$ & $\begin{array}{c}.8741 \\
p=.023\end{array}$ & $\begin{array}{c}-.1720 \\
\mathrm{~ns}\end{array}$ \\
\hline Identical & - & $\begin{array}{c}-.6402 \\
\text { ns }\end{array}$ & $\begin{array}{c}-.7827 \\
\mathrm{p}=.056\end{array}$ & $\begin{array}{c}.4911 \\
\text { ns }\end{array}$ \\
\hline Errors & & - & $\begin{array}{c}-.6004 \\
\text { ns }(p=.208)\end{array}$ & $\begin{array}{c}.0477 \\
\text { ns }\end{array}$ \\
\hline Omissions & & & - & $\begin{array}{c}-.4179 \\
\text { ns }\end{array}$ \\
\hline Additions & & & & - \\
\hline
\end{tabular}


Nonetheless, when we examine the overall results of the 6 Ss who received section A of the source text in the right ear $(\mathrm{LH})$, we note that errors decreased with age $[(\mathrm{r}=-.8391 ; \mathrm{p}=.023)$ and experience $(\mathrm{r}=-.8274 ; \mathrm{p}=.042)$ (See Table 3$)]$.

We should note that age and experience were not highly correlated: of the 4 Ss aged 40 and over, two had fewer than 18 months of experience; for the younger group comprising 12 Ss, aged from 25 to 32 years, experience varied between six months and three years, with no correlation whatsoever with age.

TABLE 4

Means and ranges for the four measures for the experienced group ( $n=4$; experience 7 years or more) and the least experienced group ( $\mathrm{n}=12$; experience 3 years and less)

\begin{tabular}{|l||c|c||c|c|}
\hline \multicolumn{1}{|c||}{} & \multicolumn{2}{c||}{ Experience +} & \multicolumn{2}{c|}{ Experience - } \\
\hline \multicolumn{1}{|c||}{} & Mean & Range & Mean & Range \\
\hline Identical/Similar & 63.46 & $58.45-75.25$ & 61.03 & $39.34-75.18$ \\
\hline Errors & 11.59 & $6.03-15.19$ & 12.96 & $4.46-21.51$ \\
\hline Omissions $^{\star}$ & 24.66 & $14.41-35.52$ & 26.18 & $19.52-48.87$ \\
\hline Additions & 19.25 & $16.78-21.38$ & 18.40 & $9.05-32.05$ \\
\hline
\end{tabular}

${ }^{*}$ significant at the .05 level

As can be seen from Table 4, long-term experience, however, seems to be important. For the four Ss with seven years' experience or more, the average scores for identical and similar propositions varied from 58.45 to 75.25 with a mean of 63.46 , whereas for the Ss with three years' experience or less, it varied from 39.34 to 75.18 , with a mean of 61.03. These differences were significant at the .05 level. Similar trends were observed for errors (varying from 6.03 to 15.19 with a mean of 11.59 for the more experienced group and from 4.46 to 21.51 with a mean of 12.96 for the least experienced group; ns), for omissions (varying from 14.41 to 35.52 with a mean of 24.66 for those with more experience and from 19.52 to 48.87 with a mean of 26.18 for those with the least experience; ns) and for additions (varying from 16.78 to 21.38 with a mean of 19.25 for the more experienced group and from 9.05 to 32.05 with a mean of 18.40 for the least experienced group; ns). What is striking is the relatively wide range of scores observed in the least experienced group. The small number of experienced interpreters does not entitle us, however, to be very conclusive about it.

\section{Relations between onset of bilinguality and measures of interpretation}

As mentioned earlier, of the $16 \mathrm{Ss}$, only 12 could be identified beyond doubt as infant/childhood bilinguals or adolescent bilinguals. Because of the small number of Ss in each group (6), Levene's Test for Equality of Variances was used to compare the means of the four measures. None of the comparisons turned out significant and no trend could be observed (e.g., the mean of the correct proposition was 61.70 for the infant/childhood bilinguals and 63.77 for the adolescent bilinguals; $\mathrm{F}=.960 ; \mathrm{p}=.35$ ) (errors: -.42 and -.42) (omissions 14.41 and 12.61; $\mathrm{F}=.227 ; \mathrm{p}=.644$ ) (additions: $24,24$ and 23,$61 ; \mathrm{F}=.300 ; \mathrm{p}=.596)$. 
Because of the small number of Ss, no statistics could be calculated to compare the bilinguals who received section $A$ in the LE versus those in the RE. Of the 6 Ss who received section $A$ in the LE, 3 were infant bilingual and 3 were adolescent bilinguals. Not even a trend indicated a possible difference.

In conclusion, we found no evidence that the age of bilingual acquisition influences hemisphere preferences in interpreters in any way. Experience influences the quality of interpretation in an unexpected way: the more the experience, the better the interpretation, regardless of the ear of input. Is the skilled interpreter capable of making better use of hemispheric control? This interesting possibility remains to be determined. Studies by Gran \& Fabbro (1988) and by Spiller-Bosatra, Darò, Fabbro and Bosatra (1990) indicate lesser hemispheric specialization in interpreters than in monolinguals. The data we obtained point to a possible difference in strategies and lead us to pose the following question: Have skilled interpreters learned to make better use of strategies involving both hemispheres, and especially when the more appropriate hemisphere should be self-stimulated? In other words, we suggest that research now should proceed as quickly as possible to the macrostructure of a text (RH).

These results fall in line with the decreased lateralization in interpreters observed by the Trieste School and with the increase in the quality of interpretation observed in skilled interpreters. Most of the studies on hemispheric preferences in interpreters fractured the linguistic task or looked at limited indices of linguistic output. By using a propositional analysis, we attempted to have a more global approach towards the task.

Although we are dealing with data from a pilot study, the results obtained tend to indicate that hemispheric preferences for linguistic analysis might be much more under a voluntary control than we expected, or rather that the choice of strategies can be modified by learning even in adulthood. Although we are dealing with data concerning a very small number of Ss, they do support the idea that whatever strategies might be acquired through bilingual experience, they seem to be independent of whatever strategic control is developed through learning interpretation skills. The data support the idea that, more than a difference in hemispheric preferences, a change in the choice of strategies might develop for a similar task according to an interpreter's experience with linguistic analysis.

\section{NOTES}

1. Entries are average D scores for 6 or 5 Ss where each individual's score is subtracted from the total group of 6 or 5 Ss.

\section{REFERENCES}

Albert, M.L. and L.K. Obler (1978): The Bilingual Brain. London: Academic Press.

BARIK, H.C. (1973): “Simultaneous interpretation: temporal and quantitative data." Language and Speech.16:237-270.

Fabbro, F., Gran, L., Basso, G. and A. Bava (1990): "Cerebral lateralization during simultaneous interpretation.” Brain and Language. 39:69-89.

Fabbro, F., Gran, B. and L. Gran (1991): "Hemispheric specialization for semantic and syntactic components of language in simultaneous interpreters." Brain and Language, 41:1-42.

GRAN, L. (1989): "Interdisciplinary research on cerebral asymmetries: significance and prospects for the teaching of interpretation." In L. GRAN and J. DodDs (Eds). The Theoretical and Practical Aspects of Teaching Conference Interpretation. Udine: Campanotto Editore: 93-100. 
Gran, L. and F. FabBro (1988): "The role of neuroscience in the teaching of interpretation." The Interpreter's Newsletter. 1: 23-41.

Gran, L. and F. Fabbro (1989): “Cerebral lateralization for syntactic and semantic components in L1 (Italian) and L2 (English) in interpreting students: training implications for simultaneous interpretation." In Proceedings of the 30th Annual Conference of the American Translation Association, Washington, D.C.: October 11-15.

Green, A., Schweda-Nicholson, N., Vaid, J., White, N. and R. Steiner (1990): “Hemispheric involvement in shadowing vs. interpretation: a time-sharing study of simultaneous interpreters with matched bilingual and monolingual controls." Brain and Language. 39: 107-133.

Hamers, J. and M. Blanc (1989): Bilinguality and Bilingualism, First Edition. 1989. Cambridge University Press, Cambridge, England. 312 pp.

Hamers, J. and M. Blanc (2000): Bilinguality and Bilingualism, Second Edition. Cambridge University Press, Cambridge, England. 468 pp.

Lemieux, S. and J.F. Hamers (1996): "Hemispheric involvement and information in simultaneous interpretation." Paper presented at AILA, Jyvaskyla, Finland, August 4-8 1996. Unpublished manuscript, Laval University, Quebec, Canada.

Kintsch, W. and van Dijk, T.A. (1978): "Toward a model of text comprehension and production." Psychological Review. 85: 363-394.

KraushaAR, B. and S. Lambert (1987): "Shadowing proficiency according to ear of input and type of bilinguality." CAAL Bulletin. 9: 1.17-31.

LAMBERT, S. (1993): "The effect of ear of information reception on the proficiency of simultaneous interpretation." Meta. 38:198-211.

Lambert S. and W.E. Lambert (1985): “Physiology: A questionnaire.” Meta.30:68-72.

Lemieux, S. (1995): "Préférence hémisphérique et traitement de l'information chez l'interprète." Thèse de doctorat, Université Laval.

Paradis, M. (1984): “Aphasie et traduction." Meta, 29: 57-67.

Spiller-Bosatra, E., Darò, V., Fabbro, F. and A. Bosatra (1990): "Audiophonological and neuropsychological aspects of simultaneous interpretation. Role of auditory shadowing. Scandinavian Audiology." 19: 81-87.

Turner, A. and E. Greene (1978): "The construction and use of a propositional text base." JSAS Catalogue of Selected Documents in Psychology. (MS No. 1713) 3:58.

VAID, J. (1984): "Visual, phonetic, and semantic processing in early and late bilinguals." In M. Paradis \& Y. Lebrun (eds.) Early Bilingualism and Child Development. Lisse: Swets \& Zeitlinger.

VAID, J. (1987): "Visual field asymmetries for rhyme and syntactic category judgements in monolinguals and fluent early and late bilinguals." Brain and Language. 30:267-77.

VAID, J. and D.G. HALL (1991): "Neuropsychological perspectives on bilingualism: right, left, and center." A. Reynolds, (ed.). Bilingualism, Multiculturalism and Second Language Learning: The McGill Conference in Honour of Wallace E. Lambert. Hillsdale, N.J.: Lawrence Erlbaum. 